The Egyptian Journal of Hospital Medicine (April 2019) Vol. 75 (3), Page 2492-2498

\title{
Optical Coherence Tomography Study of Retinal and Choroidal Changes in Patients with Chronic Obstructive Pulmonary Disease
}

\author{
Mai G. Abd El-Naser*, Heba M. Abd El-Rahman*, Zeinab R. Adawy**, Mona M. Aly* \\ Departments of Ophthalmology" and Chest"*, Faculty of Medicine (For Girls), Al-Azhar University \\ Corresponding author: Mai Gamal Abd El-Naser, Mobile: 01018321266, Email: maigamal1289@ gmail.com
}

\begin{abstract}
Background: Chronic obstructive pulmonary disease (COPD) has multi-systemic implications and comorbidities. Fine ocular structures are affected by hypoxia and systemic inflammation.

Objective: To evaluate the changes in the retina and choroid in patients with chronic obstructive pulmonary disease using spectral-domain optical coherence tomography (SD-OCT).

Patients and methods: This prospective case control study included a total of forty COPD patients and twenty ageand sex-matched healthy individuals as control group; both eyes were included. COPD patients were divided into two subgroups; a group with mild to moderate COPD and another group with severe to very severe COPD according to the Global Initiative for COPD guideline. COPD patients were subjected to spirometry. Arterial blood gas analysis was performed to determine hypoxic state. The subfoveal choroidal thickness (SFCT), macular thickness (MT) and retinal nerve fiber layer (RNFL) thickness were measured using SD-OCT and compared between groups.

Results: There was no statistically significant difference between groups according to demographic data. Mean SFCT was statistically significantly thinner in COPD groups than in the control group; and this thinning was more pronounced with increase in the severity of COPD. As regard to MT, no statistically significant difference was observed between groups $(\mathrm{p}=0.691)$. Peripapillary RNFL was significantly thinner in COPD group than the control group in all quadrants except the superior one.

Conclusion: Changes in the SFCT and RNFL thickness could be used as indicators for the severity of COPD.

Key words: Chronic obstructive pulmonary disease, subfoveal choroidal thickness, retinal nerve fiber layer thickness, macular thickness.
\end{abstract}

\section{INTRODUCTION}

Chronic obstructive pulmonary disease (COPD) is the fourth leading cause of global death and is a major cause of chronic morbidity and mortality worldwide ${ }^{(1)}$. It is considered a multi-systemic disease that is related to abnormal inflammatory response of the airways and the lungs to noxious particles or gases resulting in progressive permanent air-flow restriction ${ }^{(2-5)}$.

This inflammatory process may "spill" over into the systemic circulation, promoting a generalized inflammatory reaction. Also, the resultant tissue hypoxia is implicated in the development of the extrapulmonary manifestations of COPD ${ }^{(6,7)}$.

Fine ocular structures are thought to be affected by hypoxia and systemic inflammation, including the choroid, macula and retinal nerve fiber layer (RNFL) that can be thoroughly assessed by means of spectraldomain optical coherence tomography (SD-OCT) ${ }^{(5,8)}$.

SD-OCT is a non-invasive imaging technique that provides cross-sectional images of the retina and optic nerve head in high resolution ${ }^{(9)}$. Enhanced-depth imaging optical coherence tomography (EDI-OCT) is a recent modification to the standard SD-OCT technique. It is able to image the choroid with reasonable clarity ${ }^{(10)}$.
The current study was conducted to evaluate the changes in the retina and choroid in patients with chronic obstructive pulmonary disease using spectraldomain optical coherence tomography.

\section{SUBJECTS AND METHODS}

Ethical approval: This prospective case control study was approved by the Medical Ethics Committee of the Faculty of Medicine (for Girls), Al-Azhar University and a written informed consent was obtained from all included participants. It was done adhering to the principles of the Declaration of Helsinki guidelines. The study was conducted at the Chest and Ophthalmology Departments of Al-Zahraa University Hospital, between November 2018 and February 2019. Study Population:

A total of 40 patients with COPD (G1) and 20 healthy controls (G2) of similar age and gender were evaluated within the scope of this study. Both eyes were included if meet the inclusion and none of the exclusion criteria. COPD subjects were diagnosed according to the Global Initiative for Chronic Obstructive Lung Disease criteria (GOLD). Based on GOLD, 2017 (11), COPD patients were further subclassified according to disease severity into two groups; G1a included patients with mild to moderate 
COPD and G1b included patients with severe to very severe COPD.

Inclusion criteria were best corrected visual acuity of $6 / 12$ or better, a spherical refractive error less than $\pm 3 \mathrm{D}$ and astigmatic refractive error less than $\pm 3 \mathrm{D}$ and intraocular pressure (IOP) $<21 \mathrm{mmHg}$.

\section{Exclusion criteria:}

Systemic exclusion criteria included patients with diabetes mellitus, hypertension, decompensated heart failure, autoimmune diseases and chest diseases other than COPD.

Ocular exclusion criteria included insufficient media clarity, history of previous laser treatment, previous ocular surgeries (except for uncomplicated cataract surgery), ocular trauma, amblyopia, glaucoma and posterior segment pathology e.g. age-related macular degeneration, choroidal neovascularization, myopic atrophy, uveitis and optic neuropathy.

Examination Protocol and Study Measurements: Chest examination: Plain X-ray chest, posteroanterior view was done. Pulmonary function tests (Spirometry) were performed using Spirometer Spirosift 5000 (Fukuda Denshi, USA). Spirometry was done according to European Respiratory Society/American Thoracic Society guidelines for tests of pulmonary function ${ }^{(12)}$. The forced expiratory volume in $1^{\text {st }}$ second $\left(\mathrm{FEV}_{1}\right)$, forced vital capacity (FVC) and the ratio $\mathrm{FEV}_{1} / \mathrm{FVC}$ were measured. All subjects were given verbal encouragement during the procedure. Spirometric indices were calculated using the best out of three technically satisfactory performances. All values were expressed as percentages of the predicted normal values for age, sex, and height. COPD patients were classified according to the severity of airflow limitation based on postbronchodilator $\mathrm{FEV}_{1}$ (Table 1).

To determine hypoxic state, resting arterial blood gas (ABG) samples were taken while subjects in sitting position in ambient room air using blood gases analyzer Rapid Lab 248(Siemens Medical Solutions, Malvern, USA). The following parameters were recorded $\mathrm{pH}$, oxygen saturation (sat. $\left.\mathrm{O}_{2}\right)$, arterial $\mathrm{O}_{2}$ tension $\left(\mathrm{PaO}_{2}\right)$, and arterial $\mathrm{CO}_{2}$ tension $\left(\mathrm{PaCO}_{2}\right)$.

Table (1): Classification of Severity of Airflow Limitation in COPD Patients

\begin{tabular}{|c|c|c|}
\hline Stage & Severity & Post-Bronchodilator FEV \\
\hline $\mathbf{1}$ & Mild & $>80 \%$ \\
\hline $\mathbf{2}$ & Moderate & $50 \%-80 \%$ \\
\hline $\mathbf{3}$ & Severe & $30 \%-50 \%$ \\
\hline $\mathbf{4}$ & Very severe & $<30 \%$ \\
\hline \multicolumn{2}{|c}{ (GOLD) } \\
(11)
\end{tabular}

\section{Ocular Examinations}

All participants underwent a comprehensive ophthalmic examination including uncorrected visual acuity (UCVA) and best corrected visual acuity (BCVA) assessment, air-puff tonometry using a noncontact NT-510 tonometer (Nidek Co. LTD, Japan ), slit lamp biomicroscopic examination and dilated fundus examination with $+90 \mathrm{D}$ non-contact lens.

Optical Coherence Tomography Measurements:

Optical coherence tomography scanning with OCT-RTVue XR Avanti system (Optovue Inc., Fremont, USA) was used to measure subfoveal choroidal thickness (SFCT), macular thickness (MT) and peripapillary RNFL thickness. A motion tracking system was turned on during image acquisition to minimize motion artifacts. The SFCT was measured manually with the help of the device software using EDI mode and the white/black mode for better contrast. The SFCT was measured from the high definition (HD) line scan. The SFCT was defined as the vertical distance from the inner surface of the sclera to the outer part of the hyper-reflective line corresponding to the retinal pigment epithelium. The chorio-scleral interface was clearly visualized in all the measurements. For MT measurements, only the central $1 \mathrm{~mm}$ circle was assessed using the macular thickness map scan. For the peripapillary RNFL analysis, a 360-degree, $3.45 \mathrm{~mm}$ diameter peripapillary circle scan was performed using the standard protocol for RNFL assessment, and the thicknesses of all the quadrants (inferior, superior, nasal and temporal) were recorded separately, as well as the overall average thickness. All ocular examinations were performed between 10 am -11 am to eliminate diurnal variations in the measurements.

\section{Statistical analysis}

Recorded data were analyzed using the statistical package for social sciences, version 20.0 (SPSS Inc., Chicago, Illinois, USA). Quantitative data were expressed as mean \pm standard deviation (SD). Qualitative data were expressed as frequency and percentage.

\section{The following tests were done:}

- Independent-samples t-test of significance was used when comparing between two means.

- A one-way analysis of variance (ANOVA) when comparing between more than two means, followed by post hoc analysis using LSD test.

- Chi-square (x2) test of significance was used in order to compare proportions between qualitative parameters. 
- Pearson's correlation coefficient (r) test was used to assess the degree of association between two sets of variables.

- The confidence interval was set to $95 \%$ and the margin of error accepted was set to $5 \%$. So, the probability ( $p$-value) was considered significant as the following:

- p-value $<0.05$ was considered significant (S).

- p-value $<0.001$ was considered as highly

significant (HS).

- p-value $>0.05$ was considered non-significant

(NS).

\section{RESULTS}

Demographic and Clinical characteristics of the Study Population (Table 2):

The current study included 120 eyes of 60 participants divided into 80 eyes of 40 COPD patients (G1) and 40 eyes of 20 healthy participants as a control group (G2). COPD patients were further sub-classified into: G1a included 42 eyes of 21 patients with mild to moderate COPD and G1b included 38 eyes of 19 patients with severe to very severe COPD. There was no statistically significant difference between groups according to the demographic data $(p>0.05)$. There was also no statistically significant difference between groups according to BCVA ( $p>0.05)$. IOP was statistically significantly different between groups and it was higher in G1b group than the other two groups.

Pulmonary Measurements of the COPD groups (Table 3):

According to the results of spirometry, COPD patients were classified into 4 grades; grade I (17.5\%), grade II (35\%), grade III $(27.5 \%)$ and grade IV (20\%) as shown in Figure (1). There was a statistically highly significant difference between mild to moderate (G1a) and severe to very severe (G1b) according to spirometry. The oxygen saturations $\left(\right.$ sat. $\mathrm{O}_{2}$ ) of the patients in the severe to very severe group $(\mathbf{G 1 b})$ were highly statistically significantly lower than those in the mild to moderate (G1a) group. A statistically significant difference was observed between the two groups according to $\mathrm{PaCO}_{2}$ and $\mathrm{PaO}_{2}$.

Table (2): Demographic and Clinical characteristics of the Study Population

\begin{tabular}{|l|c|c|c|c|c|}
\hline \multicolumn{1}{|c|}{ Parameter } & $\begin{array}{c}\text { Group Ia: Mild } \\
\text { to moderate } \\
\text { COPD }(\boldsymbol{n = 2 1 )}\end{array}$ & $\begin{array}{c}\text { Group Ib: } \\
\text { Severe to very } \\
\text { severe COPD } \\
(\boldsymbol{n = 1 9 )}\end{array}$ & $\begin{array}{c}\text { Group II: } \\
\text { Control } \\
(\boldsymbol{n}=\mathbf{2 0})\end{array}$ & F/x2\# & p-value \\
\hline Age (years) & $54.29 \pm 8.05$ & $55.05 \pm 6.90$ & $52.00 \pm 6.31$ & 1.558 & 0.126 \\
\hline BCVA & $0.95 \pm 0.09$ & $0.91 \pm 0.10$ & $0.94 \pm 0.09$ & 1.564 & 0.214 \\
\hline IOP $(\mathbf{m m H g})$ & $13.26 \pm 1.53$ & $13.97 \pm 1.42$ & $12.88 \pm 1.52$ & 5.397 & $0.006^{*}$ \\
\hline Sex & & & & & \\
\hline Female & $4(19 \%)$ & $3(15.8 \%)$ & $8(40 \%)$ & \multirow{2}{*}{$3.6456 \#$} & 0.451 \\
\hline Male & $17(81 \%)$ & $16(84.2 \%)$ & $12(60 \%)$ & & 0.45 \\
\hline
\end{tabular}

F-One Way Analysis of Variance; \# ${ }^{2}$ : Chi-square test, p-value $>0.05 \mathrm{NS}$; *p-value $<0.05 \mathrm{~S}$

Table (3): Comparison between COPD groups according to ABG and Spirometry

\begin{tabular}{|c|c|c|c|c|c|c|}
\hline \multirow[t]{2}{*}{ ABG } & \multicolumn{2}{|c|}{$\begin{array}{c}\text { Group Ia: Mild to } \\
\text { Moderate COPD }(n=42)\end{array}$} & \multicolumn{2}{|c|}{$\begin{array}{l}\text { Group Ib: Severe to Very } \\
\text { Severe COPD }(n=38)\end{array}$} & \multirow[t]{2}{*}{ t-test } & \multirow[t]{2}{*}{$p$-value } \\
\hline & Mean & \pm SD & Mean & $\pm \mathrm{SD}$ & & \\
\hline pH & 7.40 & 0.02 & 7.40 & 0.03 & 0.940 & 0.350 \\
\hline $\mathrm{PaCO}_{2}$ & 38.32 & 4.52 & 41.52 & 9.08 & $2.022-$ & $* 0.047$ \\
\hline $\mathrm{Pa} \mathrm{O}_{2}$ & 75.85 & 9.71 & 71.23 & 11.91 & 1.910 & $* 0.049$ \\
\hline Sat. $\mathrm{O}_{2}$ & 95.40 & 1.41 & 93.33 & 2.52 & 4.580 & $<0.001 * *$ \\
\hline \multicolumn{7}{|l|}{ Spirometry } \\
\hline$\% \mathrm{FEV}_{1}$ & 68.33 & 19.75 & 33.42 & 10.25 & 9.767 & $<0.001 * *$ \\
\hline$\%$ FVC & 80.48 & 22.05 & 50.47 & 18.12 & 6.607 & $<0.001 * *$ \\
\hline $\mathrm{FEV}_{\mathbf{1}} / \mathrm{FVC}$ & 61.90 & 8.22 & 54.31 & 10.95 & 3.527 & $<0.001 * *$ \\
\hline
\end{tabular}

t-Independent Sample t-test, p-value $>0.05 \mathrm{NS}$; *p-value $<0.05 \mathrm{~S} ; * *$ p-value $<0.001 \mathrm{HS}$

$\mathrm{PaO}_{2}$ : Partial Pressure of Oxygen, $\mathrm{Pa}_{2} \mathrm{CO}$ : Partial Pressure of carbon dioxide, sat. $\mathrm{O}_{2}$ : Arterial Oxygen Saturation,

$\mathrm{FEV}_{1}$ : Forced Expiratory Volume in the First Second, FVC: Forced Vital Capacity. 


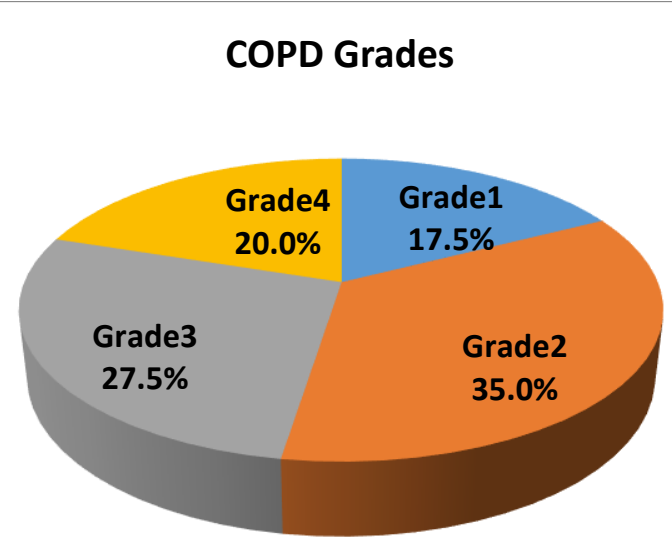

Figure 1: Pie chart showing COPD grades distribution of the patients' groups according to the results of Spirometry.

OCT Measurements of the Study Population (Table 4):

- Subfoveal Choroidal Thickness (Figure 2):

SFCT was significantly thinner in the COPD groups compared to the control group. The thinnest SFCT was observed in G1b group $(175.00 \pm 50.89 \mu \mathrm{m})$ compared to control group $(254.88 \pm 26.28 \mu \mathrm{m})$ and G1a group $(247.55 \pm 22.19 \mu \mathrm{m})$. These differences were statistically highly significant $(\mathrm{p}<0.001)$.

\section{-Macular thickness:}

There was no statistically significant difference between the three groups according to MT ( $\mathrm{p}=0.691)$.

-Peripapillary retinal nerve fiber layer thickness (Figure 3):

Peripapillary RNFL was significantly thinner in the COPD groups than the control group in all quadrants (except the superior one) and in the average values $(\mathrm{p}<0.001)$. When comparing G1a and G1b, we found a statistically significant thinning in the RNFL in inferior and temporal quadrants in G1b group.

Table (4): Comparison between all groups regarding Subfoveal Choroidal Thickness, Macular Thickness and Peripapillary RNFL Thickness

\begin{tabular}{|c|c|c|c|c|c|}
\hline \multirow[b]{2}{*}{ Parameters } & \multirow{2}{*}{$\begin{array}{c}\text { Group Ia: Mild to } \\
\text { moderate COPD } \\
(n=42) \\
\end{array}$} & \multirow{2}{*}{$\begin{array}{c}\text { Group Ib: Severe } \\
\text { to very severe } \\
\text { COPD }(n=38) \\
\end{array}$} & \multirow{2}{*}{$\begin{array}{c}\text { Group } \\
\text { II:Control } \\
(n=40) \\
\end{array}$} & \multicolumn{2}{|c|}{ ANOVA } \\
\hline & & & & $\mathbf{F}$ & p-value \\
\hline $\begin{array}{c}\text { Subfoveal Choroidal } \\
\text { Thickness }\end{array}$ & $247.55 \pm 22.19$ & $\mathbf{1 7 5 . 0 0} \pm 50.89$ & $254.88 \pm 26.28^{a b}$ & 62.025 & $<0.001 * *$ \\
\hline Macular Thickness & $248.43 \pm 12.30$ & $246.42 \pm 15.63$ & $245.80 \pm 15.41$ & 0.371 & 0.691 \\
\hline \multicolumn{6}{|c|}{ Peripapillary RNFL Thickness } \\
\hline Superior quadrant & $131.14 \pm 15.31$ & $123.79 \pm 17.80$ & $127.93 \pm 10.69$ & 2.453 & 0.090 \\
\hline Inferior quadrant & $125.95 \pm 13.82$ & $116.66 \pm 17.11 a$ & $128.70 \pm 12.12^{a b}$ & 7.418 & $<0.001 * *$ \\
\hline Nasal quadrant & $86.38 \pm 11.14$ & $83.39 \pm 13.60$ & $91.90 \pm 8.35^{\mathrm{ab}}$ & 5.835 & $\mathbf{0 . 0 0 4}^{*}$ \\
\hline Temporal quadrant & $83.69 \pm 11.05$ & $75.13 \pm 12.10 a$ & $86.10 \pm 9.19^{\text {ab }}$ & $\mathbf{1 1 . 0 0 2}$ & $<0.001 * *$ \\
\hline Average & $106.82 \pm 8.80$ & $99.76 \pm 12.17 a$ & $108.68 \pm 6.93^{\text {ab }}$ & 9.542 & $<0.001 * *$ \\
\hline
\end{tabular}

F-One Way Analysis of Variance

p-value $>0.05 \mathrm{NS}$; *p-value <0.05 S; **p-value <0.001 HS

Post HOC: a: Significant difference with group Ia; b: Significant difference with Ib 


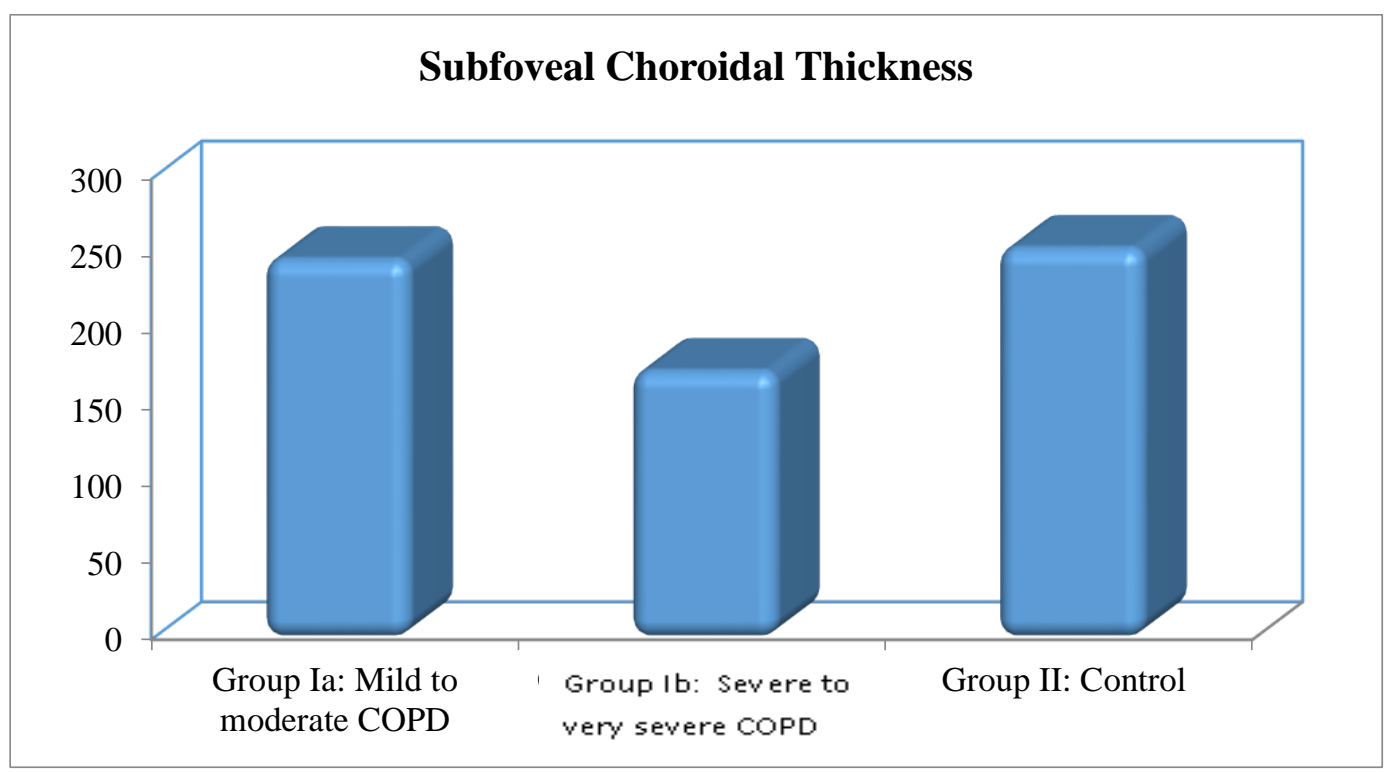

Figure 2: Bar chart demonstrating the comparison between the three groups regarding the Subfoveal Choroidal Thickness

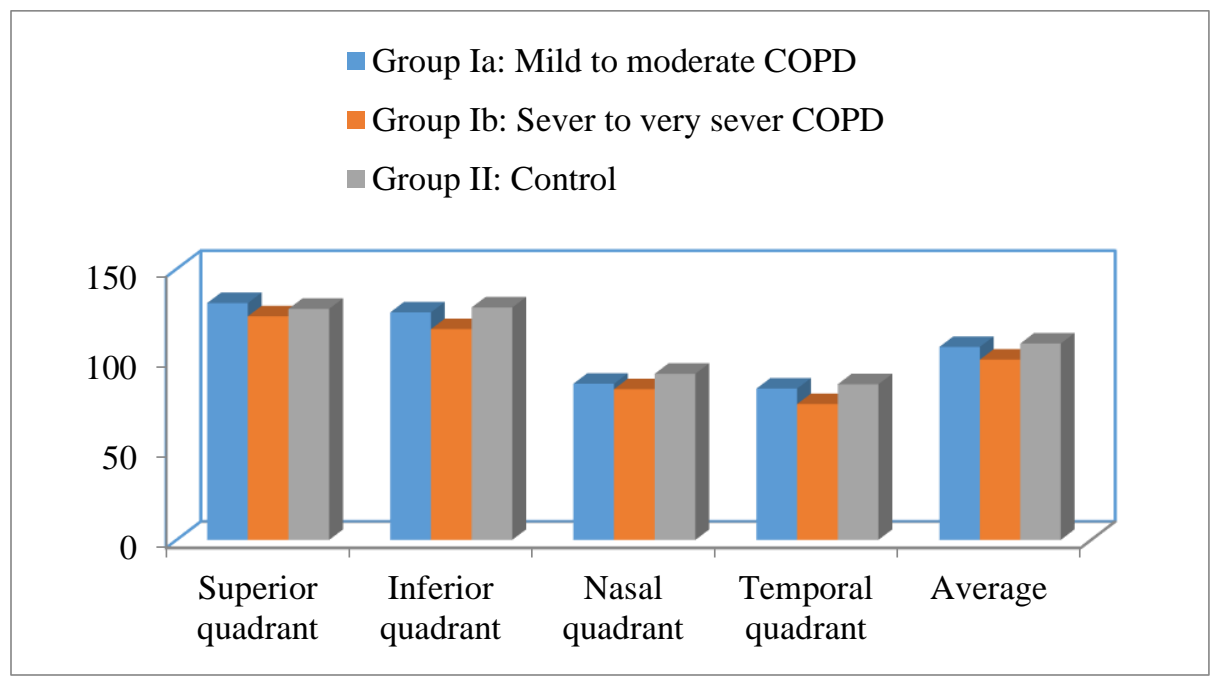

Figure 3: Bar chart showing comparison between the three groups according to Peripapillary RNFL thickness.

\section{Correlation between OCT Measurements and Pulmonary Measurements of COPD Groups:}

\section{- Subfoveal Choroidal Thickness:}

In the G1a group, there was a significant positive correlation between SFCT and $\mathrm{Pa} \mathrm{O}_{2}, \mathrm{O}_{2}$ saturation, $\mathrm{FEV}_{1}$ and $\mathrm{FEV}_{1} / \mathrm{FVC}$ (Pearson's correlation coefficients (r) of $0.372,0.511,0.424$ and 0.536 with $\mathrm{p}$ value of $0.015,0.001,0.005$ and 0.000 respectively).

\section{-Macular Thickness:}

In the G1a group, there was a significant positive correlation between MT and FEV ${ }_{1}$ (Pearson's correlation coefficients (r) of 0.469 with $\mathrm{p}$ value of 0.002).

In the G1b group, there was a significant positive correlation between MT and FVC (Pearson's correlation coefficients ( $r$ ) of 0.503 with $p$ value of 0.001); while there was a statistically significant negative correlation between the MT and $\mathrm{FEV}_{1} / \mathrm{FVC}$ (Pearson's correlation coefficients ( $r$ ) of - 0.504 with $p$ value of 0.001).

\section{DISCUSSION}

Systemic inflammation and hypoxia are being recognized as a risk factor for a variety of different COPD related complications; that may affect fine 
ocular structures as well ${ }^{(5,6,8)}$. The effect of COPD over the ocular structures was highlighted by the current study. We found a significantly lower SFCT in COPD patients compared to the control group. This thinning was also related to the disease severity. The thinnest SFCT was observed in the severe to very severe group (G1b). This choroidal thinning could be related to increased vascular resistance and reduced blood flow in patients with COPD ${ }^{(13)}$.

Similar findings was observed by Kocamış and Zorlu $^{(14)}$. They reported significant decrease in the SFCT in COPD patients during disease exacerbation and stability compared to the control group in their study. The choroid, being a highly vascular tissue can be influenced by variable systemic factors such as age, diabetes and systemic blood pressure ${ }^{(5,15,16)}$; thus the significant reduction in SFCT in COPD patients could be related to the hypoxia and systemic inflammation present in the disease. Ugurlu et al. ${ }^{(5)}$ and Özçimen et al. ${ }^{(13)}$ observed reduced SFCT in the COPD group, although this difference was not statistically significant. Ugurlu et $\boldsymbol{a l} .{ }^{(5)}$ attributed the nonsignificant changes in SFCT to activated autoregulatory mechanisms of choroidal blood flow in response to hypoxia. These auto-regulatory mechanisms prevented exaggerated alterations in choroidal thickness. They stated that this nonsignificant subfoveal choroidal thinning might be attributable to aging.

The retina receives its blood from both choroidal and retinal vasculature. A high level of oxygen extraction and a low level of blood flow characterize the retinal blood flow. The retinal circulation, unlike the choroid does not have neuronal innervation. Endothelial tight junctions of the retinal pigment epithelium constitute the blood-retinal barrier (BRB). These endothelial cells take part in the local regulation which is important for optimal visual performance ${ }^{(17)}$. Endothelial cells secret endothelin-1 (ET-1) that acts as a potent vasoconstrictor and it mainly affects the vascular endothelium and pericyte interactions within the ocular microcirculation ${ }^{(18-19)}$. Hypoxic conditions induce endothelial cell dysfunction; hence the levels of ET-1 increased in the plasma and sputum samples of COPD patients in comparison to healthy individuals (20).

Owing to the exclusion of circulating hormones like ET-1 by the BRB; they cannot reach the smooth muscle cells and therefore they have no role in retinal blood flow regulation in healthy BRB ${ }^{(17)}$. Thus the retina may respond to chronic hypoxia differently from the choroid.
In the current study we reported a statistically nonsignificant difference in MT between groups $(\mathrm{p}=0.691)$. This agrees with Ugurlu et al. ${ }^{(5)}$ who did not find significant difference in foveal thickness between healthy and COPD subjects.

The chronic systemic inflammation and hypoxic environment in COPD may cause a disturbed oxidantantioxidant balance, leading to nerve fiber loss and ganglion cell death. The ultimate result is decreased

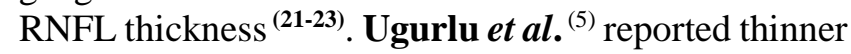
RNFL thickness in all quadrants in COPD patients, although only inferior quadrant measurements were statistically significant. They attributed these findings to hypoxia and changes in retinal vessel diameter. In their study, they observed significantly larger diameter of the retinal vein in the COPD group than in the control group. They claimed that increased retinal vessels diameter may result in reduction of the RNFL thickness. Similar results were observed by Gok $\boldsymbol{e t}$ $\boldsymbol{a l} .{ }^{(24)}$; they reported a significantly lower average and nasal RNFL thickness in the COPD group compared to the control group. They postulated a link between the disease severity and RNFL loss as evidenced by the great reduction in RNFL thickness in patients with severe COPD.

These results were also emphasized by our study. In the COPD group, we found significantly thinner average and segmental peripapillary RNFL in all quadrants except the superior one compared to the control group. This thinning was related to disease severity, as the reduction in RNFL thickness was most obvious in the inferior and temporal quadrants in G1b group. On the contrary to Kocamış and Zorlu ${ }^{(14)}$ who found non-significant difference between the mean RNFL thicknesses of the COPD patients compared to the control group. Özçimen et al. ${ }^{(13)}$ reported a nonsignificant reduction in RNFL thickness values of the COPD group than those of the control group $(\mathrm{p}=0.111)$.

For proper analysis of the results, subjects in our study were age and gender matched. Those with high refractive errors were excluded. Ocular measurements were taken at specific time of the day to avoid diurnal fluctuation. In addition, COPD group included all grades of the disease. However, some limitations are present in the current study. The limited number of subjects participating is a major limitation to our study. In addition, longer follow up time is needed to assess disease progression. 


\section{CONCLUSION}

Reduced SFCT and RNFL thinning may be attributed to chronic inflammation and hypoxia in subjects with COPD. These changes could be used as indicators for the disease severity.

\section{REFERENCES}

1. Mannino DM, Ford ES, Redd SC (2003): Obstructive and restrictive lung disease and markers of inflammation: data from the Third National Health and Nutrition Examination. Am J Med.,114(9):758-622.

2. Agusti A, Soriano JB (2008): COPD as a systemic disease. COPD.,5(2):133-138.

3. Asia Pacific COPD Roundtable Group (2005): Global Initiative for chronic obstructive lung disease strategy for the diagnosis, management and prevention of chronic obstructive pulmonary disease: an Asia-Pacific perspective. Respirology,10(1):9-17.

4. Ghee YT, Mustapha M, Harun R et al. (2017): Retinal nerve fiber layer thickness in chronic obstructive pulmonary disease: An optical coherence tomography study. Asian J Ophthalmol.,15:151-158.

5. Ugurlu E, Pekel G, Altinisik G et al.(2018): New aspect for systemic effects of COPD: eye findings. Clin Respir J., 12(1):247-252.

6. Gan WQ, Man SF, Senthilselvan A et al. (2004): Association between chronic obstructive pulmonary disease and systemic inflammation: a systematic review and a meta-analysis. Thorax, 59(7):574-580.

7. Vernooy JH, Küçükaycan M, Jacobs JA et al. (2002): Local and systemic inflammation in patients with chronic obstructive pulmonary disease: soluble tumor necrosis factor receptors are increased in sputum. Am J Respir Crit Care Med.,166(9):1218-1224.

8. El Wahsh RA., Yousif M, Ibrahim AM (2018): Retinal vascular tortuosity in patients with obstructive sleep apnea-chronic obstructive pulmonary disease overlap syndrome. Egypt J Chest Dis Tuberc., 67 (1):9-16

9. Adhi M, Duker JS (2013): Optical coherence tomography-current and future applications. Curr Opin Ophthalmol., 24(3):213-221.

10. Wong IY, Koizumi H, Lai WW (2011): Enhanced depth imaging optical coherence tomography. Ophthalmic Surg Lasers Imaging, 42:75-84.

11. Global Initiative for Chronic Obstructive Lung Disease (2017): Global Strategy for the Diagnosis, Management and Prevention of COPD, Available from: http://goldcopd.org/.
12. Miller MR, Crapo R, Hankinson $J$ et al. (2005): General considerations for lung function testing. Eur Respir J., 26(1): 153-61.

13. Özçimen M, Sakarya Y, Kurtipek E et al. (2016): Peripapillary choroidal thickness in patients with chronic obstructive pulmonary disease. Cutan Ocul Toxicol.,35(1):26-30.

14. Kocamış Ö, Zorlu D (2018): Choroid and Retinal Nerve Fiber Layer Thickness in Patients with Chronic Obstructive Pulmonary Disease Exacerbation. J Ophthalmol., 2:1-5

15. Manjunath V, Taha M, Fujimoto JG et al. (2010): Choroidal thickness in normal eyes measured using cirrus HD optical coherence tomography. Am J Ophthalmol., 150(3): 325-329.

16. Xu J, Xu L, Du KF et al. (2013): Subfoveal choroidal thickness in diabetes and diabetic retinopathy. Ophthalmology, 120(10):2023-2028.

17. Luo X, Shen Y, Jiang M et al. (2015): Ocular Blood Flow Autoregulation Mechanisms and Methods. J Ophthalmol., (12):1-7.

18. Fuchsjäger-Mayrl G, Luksch $A$, Malec $M$ et al. (2003): Role of endothelin-1 in choroidal blood flow regulation during isometric exercise in healthy humans. Invest Ophthalmol Vis Sci., 44(2):728-733.

19. Polak K, Luksch A, Frank B et al. (2003):Regulation of human retinal blood flow by endothelin-1.Exp Eye Res., 76(5): 633-640.

20. Roland M, Bhowmik A, Sapsford RJ et al. (2001): Sputum and plasma endothelin-1 levels in exacerbations of chronic obstructive pulmonary disease. Thorax, 56(1): 30-35.

21. Evans RA, Morgan MD (2014): The systemic nature of chronic lung disease. Clin Chest Med., 35(2): 283-293.

22. Domej W, Oettl K, Renner W (2014): Oxidative stress and free radicals in COPD-implications and relevance for treatment. Int J Chron Obstruct Pulmon Dis., 9(1):1207-1224.

23. Palombi K, Renard E, Levy P et al. (2006): Nonarteritic anterior ischaemic optic neuropathy is nearly systematically associated with obstructive sleep apnoea. Br J Ophthalmol., 90(7): 879-882.

24. Gok M, Ozer MA, Ozen S et al. (2018): The evaluation of retinal and choroidal structural changes by optical coherence tomography in patients with chronic obstructive pulmonary disease. Curr Eye Res., 43(1):116-121. 